\title{
SOFRIMENTO PSÍQUICO DO TRABALHADOR DA SAÚDE DA FAMÍLIA NA ORGANIZAÇÃO DO TRABALHO
}

\author{
Sandra Fogaça Rosa Ribeiro* \\ Sueli Terezinha Ferreira Martins ${ }^{\#}$
}

\begin{abstract}
RESUMO. Desde a regulamentação do Sistema Único de Saúde (SUS) as transformações na saúde pública têm se refletido na organização do trabalho. A Estratégia Saúde da Família (ESF), uma das medidas para tornar realidade essas mudanças, constituiu-se como objeto desta pesquisa, cujo objetivo foi identificar a relação entre o sofrimento psíquico do trabalhador e a organização do trabalho na ESF. A fundamentação teórica foi o Materialismo Histórico, com contribuições da Psicologia Social, da Psicodinâmica do Trabalho e da Saúde Coletiva, possibilitando o entendimento do sofrimento psíquico na organização do trabalho orientada pela lógica capitalista. A observação participante e entrevistas foram utilizadas no levantamento dos dados, numa abordagem qualitativa. A análise foi realizada com a divisão do estudo em temas e subtemas, procedendo-se à análise de conteúdo. Os três temas foram: "Implicações de ordem pessoal”, "O cotidiano do trabalho de atenção" e "A infraestrutura institucional", não se mostrando as relações entre dificuldades estruturais e funcionais na organização do trabalho e o sofrimento psíquico.
\end{abstract}

Palavras-chave: sofrimento psíquico, Programa Saúde da Família, organização do trabalho.

\section{PSYCHOLOGICAL DISTRESS OF THE FAMILY HEALTH WORKER IN THE ORGANIZATION OF WORK}

\begin{abstract}
Since the regulation of the Unique Health System (SUS), the transformations in the public health have brought reflexes in the work organization. The Family's Health Strategy (ESF), one of the measures to bring into reality the extolled changes, was the scenery of this research, whose aim was to identify the relation between the psychological distress of the worker and the organization of work in the ESF. The theoretical foundation was historical materialism, with contributions of Social Psychology, Psychodynamics of Work and Health, enabling the understanding of psychological distress in the organization of work, permeated by the capitalist logic. Participant observation and interviews were used in the survey data in a qualitative approach. The analysis was performed using themes and subthemes, with content analysis. The three themes were: implications of personal order, everyday work of care, and the institutional infrastructure, showing relationships between functional and structural difficulties in the organization of work and psychological distress.
\end{abstract}

Key words: Psychic distress, family health program, work organization.

\section{SUFRIMIENTO PSÍQUICO DEL TRABAJADOR DE LA SALUD DE LA FAMILIA Y LA ORGANIZACIÓN DEL TRABAJO}

RESUMEN. Desde la reglamentación del Sistema Único de Salud (SUS), as transformaciones el campo de la salud pública han traído reflexos em la organización del trabajo. La Estrategia Salud de la Familia (ESF), uma de las medidas para tornar realidad los cambios se configuro como escenario de uma investigación, cuya objetivo fue identificar la relación entre sufrimiento psíquico del trabajador y organización del trabajo em la ESF. La fundamentación teórica fue el materialismo histórico, com contribución del la psicodinámica del trabajo, Psicología Social y Salud Colectiva, posibilitó el entendimiento del sufrimiento psíquico em la organización del trabajo, permeada por la lógica capitalista. La observación participante y

Mestre em Saúde Coletiva pela Universidade Estadual Paulista Júlio de Mesquita Filho, Docente da Faculdade Ingá/Uningá, Brasil.

\# Doutora em Psicologia (Psicologia Social) pela Pontifícia Universidade Católica de São Paulo, Professor assistente doutor da Universidade Estadual Paulista Júlio de Mesquita Filho , Brasil 
entrevistas fueron utilizadas para la cosecha de los dados em um enfoque cualitativo. El análisis fue realizado por temáticas y subtemáticas, com análisis de contenido. Las três temáticas fueron impliciones de orden personal, el cotidiano de trabajo de atención y la infraestructura institucional, mostrando relaciones entre dificultades estructurales y funcionales en la onganización del trabajo y el sufrimiento psíquico.

Palabras-clave: Sufrimiento psíquico, programa de salud familiar, organización del trabajo.

Desde a regulamentação do Sistema Único de Saúde (SUS), as mudanças ocorridas nos últimos anos nas políticas públicas de saúde têm desencadeado novos modelos de atenção à saúde. A Estratégia Saúde da Família (ESF) foi reconhecida como uma medida para tornar realidade tais mudanças, por meio de uma ação integralizada de equipe, da atenção territorializada, da compreensão da família de forma ampla e de intervenções baseadas no estabelecimento de vínculos entre o trabalhador de saúde e a população (Brasil, 2006). Uma nova organização do trabalho exige mudanças nas práticas cotidianas do trabalhador, e no caso da ESF as mudanças ainda estão na fase de preparação e o trabalhador necessita de capacitação para enfrentá-las. Preocupações referentes a essa situação motivaram a investigação sobre a relação entre o sofrimento psíquico do trabalhador e a organização do trabalho em uma equipe da Estratégia Saúde da Família.

Para o entendimento do sofrimento psíquico diante dessas transformações na organização do trabalho, baseadas na lógica capitalista, foram utilizados os pressupostos teóricos do materialismo histórico-dialético. A investigação busca revelar as reais relações dinâmico-causais subjacentes a esse fenômeno, o qual será estudado, nesse processo de mudanças e de constante movimento, enquanto um fenômeno histórico e contraditório, pois nele existe um sistema dinâmico de significados em que o afetivo e o intelectual se unem (Vigotski, 1931/1995).

Além disso, para destacar o caráter subjetivo do elemento sofrimento psíquico em relação à organização do trabalho, foram aproveitadas contribuições da Psicodinâmica do Trabalho, da Psicologia Social e da Saúde Coletiva. Essa integração teórica considerou as diferenças entre as abordagens, mas entendeu que, segundo Sato e Bernardo (2005) e Seligmann-Silva (2003), a complexidade do problema do desgaste mental no trabalho dentro do contexto da reestruturação produtiva requer a contribuição de diversas abordagens teóricas, com os devidos ajustes. Nas palavras de Seligmann-Silva (1994,p.294),

O modelo centrado no conceito de desgaste mental pode ser tomado como um paradigma integrador, que permite compreender as interações entre os "fatores" objetivados pelos estudos do "work stress", a subjetividade e diferentes esferas da vida social, a partir dos âmbitos microssociais do local de trabalho e da família, passando pelos intermediários (empresa e comunidade), até os macrossociais, que definem desde a divisão internacional de trabalho às políticas industrial, tecnológica e salarial de cada país, balizando as relações sociais de trabalho em cada realidade.

A integração procurará explicitar pontos importantes, não só dos aspectos sociais que se originam fora do ambiente de trabalho e atingem, com maior ou menor vulnerabilidade, o trabalhador em relação aos seus aspectos patogênicos, mas também daqueles circunscritos ou específicos da gestão e da organização do trabalho (Seligmann-Silva, 1994).

$\mathrm{Na}$ perspectiva marxista, o trabalho é a transformação da natureza para benefício do homem, com intenções e desejos; por outro lado, na lógica capitalista, a matéria-prima do trabalho deixa de ser a natureza e passa a ser o próprio trabalhador, a sua força de trabalho. Nessa lógica o trabalho não atende aos interesses e desejos do trabalhador, mas aos do mercado e do capital. As consequências desse processo são a alienação do trabalho, a desvalorização, o estranhamento do trabalhador ao produto do seu trabalho e a perda da liberdade. O trabalhador é tanto menos importante quanto mais valorizado for o produto. A compartimentalização do trabalho se intensifica na mesma medida da alienação (Marx, 1844/2004).

Assim o trabalho, compreendido como categoria central, mediação da sociabilidade, criador de riquezas e possibilitador da transformação humana, provoca, contraditoriamente, a desumanização. Este processo se intensifica com as transformações que ocorrem na sociedade contemporânea, caracterizadas pelo avanço da reestruturação capitalista, que modifica as condições de trabalho, principalmente quanto às suas formas de organização e controle. A área da saúde pública não está imune a essas transformações (Kantorski, 1997).

As investigações no campo da Saúde Coletiva e da Psicologia Social (Campos, 2002; Codo, Sampaio \& Hitomi, 1993; Franco \& Merhy, 2006; Martins, 
2003; Ribeiro, Pires \& Blank, 2004; Seligmann-Silva, 2003) contribuem para a compreensão dessas questões, identificando-se na organização do trabalho em saúde as seguintes características: atos parcelares e normatizados; procedimentos estanques das categorias de profissionais; aumento da tecnologia dura em detrimento da tecnologia leve (Merhy, 2002); distanciamento do profissional/trabalhador do usuário; falta de reconhecimento de si mesmo no seu trabalho; atos e medidas de cunho higienista; terceirização; precarização das relações de trabalho; desarticulação da equipe.

Diversos autores (Matumoto, Fortuna, Mishima, Pereira \& Domingos, 2005; Pires, 2000; Silva \& Trad, 2005; Vieira \& Cordeiro, 2005) evidenciam que a situação tende a piorar, porque a produção da saúde é um processo indissociável do seu produto, é a atividade em si mesma, porém a divisão parcelar do trabalho torna-a dissociada e contraditória, implicando em perda maior da autonomia do trabalhador, que, cada vez mais especializado, perde a noção do todo, uma vez que são fragmentadas as suas ações de cuidado ao usuário. Muitas vezes o trabalhador desconhece a finalização de um procedimento que ele iniciou, mas foi finalizado por outro trabalhador, em muitos casos na mesma unidade.

Em geral os trabalhadores não consideram essas questões nrm refletem sobre elas. A falta de noção clara do trabalhador quanto aos motivos de seu sofrimento o leva a atribuir eventuais falhas a si próprio ou a um colega de trabalho. Segundo a Psicodinâmica do Trabalho, ele passa a utilizar mecanismos de defesa ou estratégias defensivas para driblar o sofrimento (Dejours, 1992). Para o autor aqui referenciado, na maioria das vezes o trabalhador não pode alterar nada nesse mundo externo, ficando à mercê de uma organização do trabalho que em nada coincide com seu próprio ritmo biológico, endócrino e psicoafetivo. Não obstante as críticas de alguns pesquisadores à concepção dejoursiana, como o fato de ela ser patologizante e individualista (Lima, 2002), os últimos trabalhos de Dejours (2004a, 2004b) explicitam a sua preocupação com o adoecimento do trabalhador em virtude da organização do trabalho, bem como o direcionamento metodológico voltado à observação dessa dinâmica organizacional, não se restringindo apenas ao discurso do trabalhador.

Heloani e Lancman (2004) destacam as seguintes etapas do processo investigativo que considera a participação dos trabalhadores, funcionários e pesquisadores em discussões grupais: 1)- análise da demanda que gera a intervenção; 2)- observação clínica e interpretação ou identificação dos elementos subjetivos das sessões grupais e atribuição de sentidos a eles por meio de conceitos; e 3) validação e refutação.

Dejours (1992) constrói a sua concepção de estratégias defensivas numa relação do trabalhador com a organização do trabalho direcionando-se à realidade social do trabalho. Como a modificação da organização do trabalho está bloqueada, o trabalhador busca modificar, transformar e minimizar sua percepção da realidade através dos mecanismos de defesa. Isto o faz sofrer, pois não modifica a realidade a ele imposta, no sentido de aliviar seu sofrimento, mas mascara essa realidade, garantindo a manutenção da produtividade e até mesmo o seu aumento. O perigo da utilização excessiva desses mecanismos é a loucura do trabalho e se constitui em ações que reforçam a alienação do trabalhador na sociedade capitalista (Dejours, 1992; Seligmann-Silva, 2003).

\section{MÉTODO}

A observação participante foi o momento inicial da pesquisa e possibilitou um conhecimento preliminar dos trabalhadores e da organização do trabalho, subsidiando a formulação da questão norteadora da entrevista no sentido de ouvir os relatos referentes ao desgaste no trabalho. Os eixos de investigação foram orientados pelos pressupostos teóricos da pesquisa: organização do trabalho na ESF, ações novas e antigas, práticas específicas e genéricas, dificuldades encontradas na execução do trabalho, rotina diária do trabalho. Os dados foram registrados em um diário de campo. Esse processo de observação prosseguiu durante toda a pesquisa.

A entrevista não estruturada foi utilizada a fim de proporcionar um espaço mais reservado para relatos de natureza delicada e pessoal. Diante de uma solicitação dos próprios trabalhadores de terem um espaço para falar do desgaste mental no trabalho ${ }^{1}$, a entrevista foi orientada pela questão: "Descreva como é o seu desgaste emocional na execução do seu trabalho nesta unidade e a repercussão disso na sua vida pessoal". As respostas foram gravadas $\mathrm{e}$ transcritas na íntegra.

Conforme Seligmann-Silva (2003, p. 1158), desgaste mental e sofrimento psíquico, remetem igualmente às reflexões teóricas feitas até agora neste trabalho. Em suas palavras, é o "modo pelo qual a interação do trabalhador com esta situação (situação

\footnotetext{
Solicitação realizada aos pesquisadores do projeto temático "Estratégias de formação e intervenção em saúde mental junto a equipes do Programa de Saúde da Família".
} 
de trabalho) repercute na subjetividade do mesmo, suscitando vivência de sofrimento".

A população constituiu-se de todos os componentes de uma equipe da Unidade Saúde da Família (USF) de um município de médio porte do Interior do Estado de São Paulo, totalizando quinze trabalhadores: cinco agentes comunitários de saúde, três auxiliares de enfermagem, uma enfermeira, dois residentes (um de enfermagem e um de medicina), uma médica, um auxiliar administrativo e uma auxiliar de serviços gerais. A caracterização sociodemográfica dos participantes é a seguinte: treze eram do sexo feminino e dois do sexo masculino; nove cursaram o Ensino Médio, dois o Ensino Superior, dois fizeram curso de pós-graduação e dois estavam por concluir cursos de mestrado; e tinham em média três anos de experiência em trabalho com Saúde da Família.

$\mathrm{O}$ critério de inclusão de todos na pesquisa foi o pressuposto de o trabalho na Saúde da Família ser feito em equipe, incluindo os residentes de enfermagem e medicina, pois participavam constantemente das atividades coletivas na unidade de saúde.

Como já colocado, a pesquisa foi realizada na perspectiva do materialismo histórico e dialético, indicado por Minayo (2004) como o que mais se presta à abordagens de questões sobre saúde/doença, sendo relevante a consideração do fenômeno dentro de uma historicidade, numa sociedade marcada pela divisão de classes.

Fundamentado nessa visão, Vigotski (1931/1995) propõe que a compreensão da história humana não está baseada somente nas consequências da natureza sobre o ser humano, mas que o ser humano também afeta a natureza, modificando-a e criando novas possibilidades de existência. Para uma análise dessa constante transformação o autor propõe três princípios de investigação: 1) analisar processos, e não objetos; 2) explicação versus descrição; e 3) o problema do "comportamento fossilizado".

Para analisar processos Vigotski aponta a necessidade de reconstruir as etapas do processo, desde sua gênese até as transformações do presente. Para distinguir explicação e descrição, recorre a dois tipos de análises: a genotípica, caracterizada pela observação da essência, e a fenotípica, caracterizada pela aparência dos fenômenos, enfatizando a importância das relações subjacentes ao fenômeno, nem sempre explícitas na sua aparência. O problema do comportamento fossilizado diz respeito aos processos mecanizados que perderam sua natureza original. Para desmontá-los é necessário focar a análise no processo em desenvolvimento, e não unicamente no produto final que se apresenta no momento da investigação (Vigotski, 1931/1995). Neste sentido, as entrevistas e a observação participante captaram o fenômeno na essência, e não na aparência, no seu processo histórico e mutável, assim como buscaram garantir a explicitação de processos já fossilizados.

Os relatos dos trabalhadores e as anotações das observações em diário de campo foram submetidos à análise temática segundo a proposta de Minayo (2004), a qual compreende três fases: 1) pré-análise; 2) exploração do material; e 3) tratamento e interpretação dos dados obtidos. A pré-análise foi realizada com uma leitura caracterizada por uma atenção flutuante, em que a subjetividade do pesquisador e a dos pesquisados se integraram para se estabelecerem, numa unidade contextual, os temas sócio-historicamente determinados. No presente estudo os participantes apontaram com trechos significativos ou representativos os subtemas que sintetizaram a essência do fenômeno. A exploração do material foi mediante sua repetida leitura, na busca de orientações para a análise propriamente dita. O tratamento e a interpretação dos resultados obtidos foram realizados por meio da busca do sentido latente ou subjacente expresso no manifesto e sua correlação com as tendências e ideologias correntes a respeito do fenômeno estudado.

O projeto foi aprovado pelo Comitê de Ética em Pesquisa da instituição onde se realizou o estudo. Os participantes foram esclarecidos sobre os objetivos da pesquisa e formalizaram seu consentimento em participar conforme as normas estabelecidas pela Portaria 196/96 do Conselho Nacional de Saúde, que prevê a preservação do anonimato e da privacidade dos sujeitos.

\section{RESULTADOS E DISCUSSÃO}

Os conteúdos das observações e entrevistas foram organizados em três temas: a) implicações de ordem pessoal, b) o cotidiano de trabalho de atenção e, c) a infraestrutura institucional (ou a ausência dela). Cada tema guarda em si a representação do todo, sofrendo seus reflexos e, ao mesmo tempo, interferindo nele.

Os depoimentos dos trabalhadores serão apresentados indistintamente da categoria profissional, exceto quando o conteúdo do depoimento tiver alguma especificidade que demande destaque do trabalhador informante.

O primeiro tema, Implicações de ordem social, desdobrou-se em alguns subtemas. O impacto inicial como trabalhador na USF (Unidade Saúde da 
Família) foi relatado com voz embargada pela emoção ante as dificuldades de trabalhar com a saúde, com a vida e com a morte, principalmente na Estratégia Saúde da Família, que envolve um contato maior com a população. Os trabalhadores mais experientes diziam: "Sofri bastante. Agora tou melhor. O tempo já passou. A gente até fala pras novas. Que acostumem com a ideia, que no começo se passa mal, entra em depressão, pressão alta [...] todas nós já passamos por isso." Embora seja inconcebível acostumar-se com o sofrimento, o relato parece indicar que com o tempo o impacto inicial era minimizado, não por diminuição do sofrimento, mas por se acostumar com ele.

Passadas as primeiras experiências, vários trabalhadores relataram um dia de explosão, pelo impacto do trabalho: "A criança teve uma máformação crânio-encefálica que rompeu $e$ teve aneurisma. Foi véspera de feriado. Fiquei supermal, chorei o dia todo, a noite inteira. E no feriado eu ligava...". Esse foi um dia específico de sofrimento maior, culminando em crises de choro, preocupação excessiva com o usuário e descontrole emocional. Outra situação demonstra um autocontrole ou punição exacerbada dos próprios erros:

\begin{abstract}
"Eu fiz uma troca de medicação. Ela (outra trabalhadora) me deu a notícia da melhor forma possível. Não foi grossa, nem repreendeu. Mas o senso de responsabilidade da gente é muito grande. Eu me repreendi. Não precisou dela me repreender. Eu mesma me repreendi. Isso me fez muito mal. Fiquei uns par de dias mal. Entrei em crise nervosa". (Entrevista)
\end{abstract}

O que é reconhecido como responsabilidade parece ser um autocontrole construído artificialmente pelas pressões da correria e dos horários rígidos a serem cumpridos. A ansiedade e o medo de ser punido desencadearam como estratégia de defesa esse autocontrole ou punição exacerbada dos próprios erros (Dejours, 1992).

Os problemas de organização do trabalho relacionados a isso apareceram num dia de reunião em que expuseram a correria, o excesso de trabalho e falta de espaço adequado.

"Uma trabalhadora aponta algumas coisas que ao seu ver estão relacionadas: falta de tempo por causa da demanda excessiva, dificuldade de dar mais tempo para um usuário e ter muitos outros aguardando, dificuldade de lidar com sofrimento, choro do usuário. Outra trabalhadora complementa com falta de privacidade nos atendimentos, às vezes salas com portas abertas, vários procedimentos juntos". (Diário de Campo)

Vários autores (Merhy, 2002; Campos, 2002; Matumoto et al., 2005; Ribeiro et al., 2004) confirmam que essas questões estão ligadas a um processo de trabalho mecanizado e parcelado, acarretando um desconhecimento do resultado do trabalho e esvaziando o seu sentido; mas o que parece é que os trabalhadores não estão nem totalmente esvaziados de sentido nem totalmente engajados, mas entre as duas possibilidades, tentando sobreviver à fragmentação.

Além de um dia de explosão, a correria do diaa-dia e o adoecimento no trabalho traziam problemas: "Eu fico assim mordendo (mostra a boca, mandíbula). Tenho que fazer o tratamento, só que é caríssimo." "Porque é muita coisa pra mim fazer, e como eu não tô dando conta...".

A tristeza por ter o que a população não tem e a identificação com os problemas da população foram dois subtemas que remeteram a uma questão central: o vínculo. O que é pressuposto da Estratégia Saúde da Família (ESF) é motivo de sofrimento, principalmente para as agentes comunitárias de saúde (ACSs) que moram no bairro. A privacidade no cuidado da própria saúde fica prejudicada, porque o atendimento no lugar que trabalha causa constrangimento. A ACS diz: "Queria falar com outra pessoa que esteja fora, não da própria unidade (unidade que trabalha)"

Por outro lado, algumas participantes buscavam alívio num dos grupos de atendimento para mulheres, coordenado pela médica e pela enfermeira da unidade. Deviam estar nos grupos como trabalhadoras, mas às vezes usufruíam do atendimento como usuárias: " $O s$ grupos. Eu acho que dos dois lados, como participante e como profissional. Seria no geral, em tudo.”. A aproximação com a população caracterizou um vínculo confuso, desenvolvido no contato contínuo. Elas não conseguem se desligar dos casos atendidos quando vão para suas casas, desenvolvendo uma mistura de amizade e intimidade, o que causa incômodo e culpa. O sofrimento e o choro foram revividos no momento da entrevista: "Você vai na casa e vê toda uma situação complicada de miséria (Choro e pausa). Então é isso, isso me causa muita tristeza (fala mais baixo)." Por outro lado, ter os mesmos problemas também causa sofrimento, como no caso desta trabalhadora: "Porque meu pai era a mesma coisa. Falava, falava com meu pai e era a mesma coisa. Ficava triste.”. 
As formas para amenizar o sofrimento expressas foram rezas, choro, psicoterapia: “É. $E$ eu tenho muita fé, [ir] a igreja e rezar bastante e colocar Deus na frente. Comigo funciona assim."; "Porque eu dormia pouco, vinha aqui trabalhava muito... E aí ficava muito cansada. Todo mundo aqui já teve um dia que chorou por conta disso.”; “É. Antes eu tava fazendo terapia, mas agora eu dei um tempo...”.

Para outros trabalhadores as saídas foram guardar o problema, ficar quieto e brincar: "Mas é muito difícil eu desabafar. É uma vez ou outra. Eu guardo pra mim."; "Estou sempre mexendo com um e com outro. Tou sempre brincando. Pra descontrair o stress. [...] Se não tiver um momento de risada, o ambiente fica muito 'bronco',".

Essas formas de lidar com o sofrimento de forma individual estão, em geral, a serviço das estratégias de defesa (Dejours, 1992; Seligmann-Silva, 1994). A brincadeira no trabalho é um exemplo disso. Assim, os trabalhadores se afastam da realidade e, consequentemente, de possibilidades reais de mudança. Quando brincam em situações de desgaste eles escamoteiam o sofrimento, mas não procuram compreendê-lo. Seria favorável que vivenciassem momentos de descontração e de risadas, desde que não fossem para tamponar o sofrimento. É um processo inconsciente, e por isso mesmo mais perigoso e propício à alienação.

O acolhimento mútuo dos trabalhadores nos momentos difíceis apareceu várias vezes: "Só sei que eu vi a bagunça e comecei a chorar. Nossa! Aí a Z. veio e: 'Calma, bem, não fica assim, vai todo mundo te ajudar...' Aí chorei, chorei, chorei...”. Essa situação ocorreu durante reformas no prédio da unidade, pela necessidade de adaptações e deslocamento dos móveis, causando angústia na trabalhadora, que levou para casa a preocupação com a desordem. Ela afirma: "De pensar na bagunça que ficou aqui, não conseguia nem fazer seus afazeres em casa, nem dormir, nem nada”. Observa-se uma atitude de solidariedade coletiva saudável, mas restrita àquele momento e insuficiente para evitar outras situações.

O segundo tema, $O$ cotidiano do trabalho de atenção, envolveu seis subtemas. A impotência no trabalho de atenção à saúde apareceu em situações de dificuldade em realizar o atendimento ao usuário, causando sofrimento. Na maioria das vezes a única estratégia que encontravam era ouvir. $\mathrm{O}$ vínculo construído com o usuário ficava sem resposta.

A angústia aparecia quando não se sabia o que fazer com a emoção por parte do usuário, como o choro:
"Eu acho que eu fiquei chocada com isso, não esperava isso. Eu tive que ficar ali do lado dela [da usuária]. Ela passando mal, chorando [...] Todo mundo quer correr pra outro lado. São pessoas que parecem... que sufocam a gente."

O trabalhador evitava que o usuário rompesse em choro, muitas vezes desviando-se do assunto delicado ou atendendo de porta aberta, mas ficava com a sensação de impotência. Por outro lado, questionavase até que ponto tinha de lidar com essas questões, se isso fazia mesmo parte do trabalho dele:

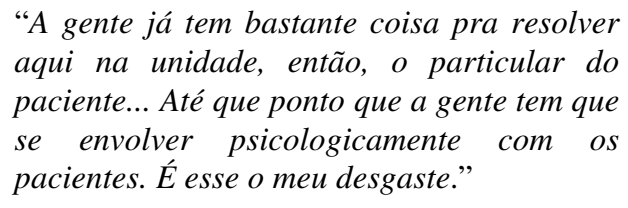

Tais relatos parecem indicar uma mistura de não saber lidar com o problema com falta de clareza quanto ao seu papel na USF. Não se sabe o que fazer com o usuário que quer ser ouvido e acolhido, mas sem queixa específica.

$\mathrm{O}$ pedido de ajuda foi contundente durante o processo da pesquisa: "Uma auxiliar de enfermagem faz uma proposta de reciclagem dos profissionais, com vivência prática, não cursos teóricos”. (Diário de Campo)

Os questionamentos realizados na observação participante junto aos trabalhadores produziram reflexões advindas da presente pesquisa sobre o sofrimento e o processo de trabalho em equipe. Seguindo a metodologia participativa, culminou num processo de educação permanente em saúde, detalhado logo a seguir.

A frustração por falta do usuário denotou uma relação de poder, e não de espaço intermediário, naturalizando o "deve ser assim", que foi frustrado com a falta de adesão do usuário ao tratamento: “...É outra coisa que chateia bastante. Aí você fala: 'Pô, você não toma certo o remédio, não faz as coisas que eu pedi!'”. Segundo Teixeira, Mishima e Pereira (2000, p.204),

um sentimento que pode aflorar em alguns profissionais é o da frustração quando percebem que agora não são mais os únicos detentores do poder de decisão, nem sempre o que ele pensa ser melhor para o paciente é realmente o que ele necessita para sobreviver e ser feliz. 
A relação de poder ficou no lugar de uma educação em saúde. Conforme estudos de Merhy, 2002 e Martins, 2003, essa atitude parece desconsiderar o espaço entre trabalhador e usuário como espaço de negociação da produção de saúde. $\mathrm{O}$ trabalhador/profissional coloca-se no lugar de saber e o usuário/paciente no lugar de não saber, sem nenhuma informação do seu próprio problema, e ao mesmo tempo é cobrado a obedecer cegamente às prescrições, que muitas vezes ele nem compreende, vendo no desacato às prescrições a única saída para se manifestar contra algo com que não concorda.

A consulta eventual, não agendada, aumentava progressivamente, sendo apontada como causa de desgaste contínuo no trabalho. A explicação do excesso das consultas eventuais é feita por alguns trabalhadores: "É uma coisa que o secretário [Secretário de Saúde] não quer que a gente coloque limites, é uma coisa política.". As pesquisadoras fazem uma proposta de ajudá-lo a discutir o problema, desencadeando um processo de educação permanente em saúde, integrando formação, teoria e prática e local de trabalho, a partir das necessidades dos trabalhadores (Ribeiro \& Martins, 2007; Brasil, 2004). Há uma diferença entre os conceitos que se tinham e do que se têm atualmente:

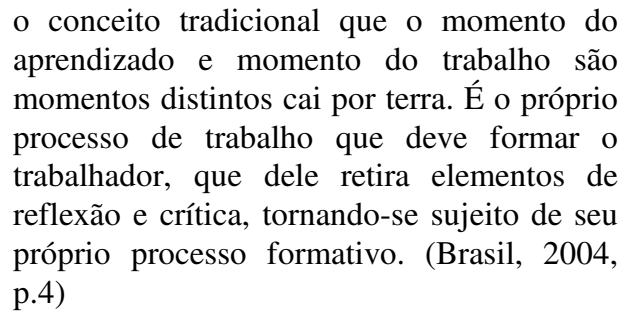

A visita como prazer, ação fundamental no trabalho de saúde da família, foi apresentada como um raro momento de prazer no trabalho: "É tranquilo. $E u$ amo fazer visita. Você sai do posto, desse ambiente aqui...". Alega-se que com elas se tem mais resolubilidade. Parece que é exatamente o momento em que a aproximação com o usuário fica mais fácil, permitindo que o trabalhador se reconheça no seu trabalho, como apontado por Marx (1844/2004).

Os grupos são expressos como fonte de sofrimento e prazer, numa situação contraditória vivenciada pelo trabalhador: "Quando a gente tá dentro do grupo a gente sabe que vai ter coisas pesadas ... Mas tem coisa legal também...”. Os grupos são identificados como mais eficazes na promoção de saúde e no desenvolvimento da autonomia que as consultas individuais. A resolubilidade é descrita como boa, mas o desgaste pela atividade é visto como ruim. O desenvolvimento do grupo não tem resultado rápido e não segue uma rotina predeterminada, aparecendo questões diversas e às vezes de difícil manejo, como observou a trabalhadora. Isso o torna inviável diante de cobranças por resultados rápidos. A ESF deveria buscar outra lógica de promoção da saúde na qual os grupos fossem mais incentivados (Franco \& Merhy, 2006; Ribeiro et al., 2004).

Sucintamente, os sentimentos de impotência contribuíram para aumentar o desgaste do trabalhador, o qual, por um lado, decidia arbitrariamente o que era melhor para o usuário, sem a adesão deste, e por outro, estagnava-se em uma escuta passiva, evitando situações que não queria vivenciar, como o choro do usuário. A correria e a fragmentação esvaziavam o sentido do trabalho e geravam um desgaste crescente, culminando num dia de explosão ou em momentos diversos de descontrole.

A Infraestrutura Institucional se caracterizou muito mais pela ausência de rede de apoio do que pela presença. $\mathrm{O}$ desgaste por falta de rede de apoio foi apontado como social, educacional e da própria saúde, principalmente na falta de efetividade dos encaminhamentos para atendimentos específicos na rede pública do município. No diário de campo está registrada a falta de organização da rede: " $O$ problema chega até aqui.[...] E daqui a gente não tem mais pra onde ir. $O$ setor terciário, o setor secundário que nos apoia é muito falho...".

O resultado da falta do trabalho em rede é a sobreposição de atendimentos, com atitudes contraditórias que sem dúvida prejudicam o usuário (Teixeira et al., 2000). A proposta de construção coletiva é compreendida pelos trabalhadores como algo que necessita de uma interface com o gestor e com a comunidade, segundo relato de uma trabalhadora, registrado no diário de campo "Q. reforça que é a construção do trabalho coletivo, mas que tem que ser levado ao conhecimento do gestor e da comunidade para ter prosseguimento.". De acordo com Silva (2002), o gestor se sensibilizaria para essa construção coletiva se houvesse uma exigência da população, que por sua vez precisaria saber de seus direitos quanto às mudanças do modelo assistencial, e o controle social teria que ser desenvolvido e incentivado para que tais processos se efetivassem; entretanto a relação com o gestor é relatada pelos trabalhadores como permeada por vigilância constante e forças desiguais, com ênfase em determinações rígidas. Uma trabalhadora diz: "Sinto que tou na mira...". Se acima se constatou que o trabalhador exercia um domínio sobre o usuário, agora é ele que se vê dominado, sem possibilidade de 
participação nas decisões concernentes a si mesmo. Estas situações de domínio se alternam, implicando no fato de que quem domina em uma relação pode ser dominado em outra (Martins, 2003).

Dejours e Bègue (2010) relatam que essas formas de gestão exercidas no contexto da reestruturação produtiva, principalmente quanto às suas formas de organização e controle, transformam a gestão em "presente de grego", que esfacela e destrói a "cidadela" do trabalho. É uma analogia que pode ser claramente observada no que a trabalhadora disse acima: "tou na mira". Essa expressão sugere que esteja numa guerra, sofrendo retaliação pelas formas perniciosas de gestão.

Em outro subtema, o trabalho em equipe, apresentou-se o problema da burocratização do trabalho e da falta de comunicação, colocadas como empecilhos para o desenvolvimento das relações em equipe. Uma trabalhadora assim expressa o seu desgaste: "Não tem o espírito de coletividade. Fala-se que tem, mas não tem. No meu modo de ver, não tem. Não existe isso. E eu sofro. Com isso eu sofro.".

Há uma tentativa de passar de equipe do tipo agrupamento para equipe integração, que requer uma reconstrução diária dos agentes do trabalho na equipe enquanto sujeitos e donos de seu próprio destino; mas como esses destinos se intercruzam, as conquistas individuais só se tornam possíveis se constituídas junto à coletividade (Peduzzi, 2001).

Tal empreendimento não é fácil e requer disponibilidade para uma prática comunicacional tolerante, permeabilidade ao novo e abertura para conhecer o trabalho do outro (Codo et al., 1993). É exatamente o que os trabalhadores já afirmaram não conseguir fazer: "Você vê que precisa, mas não tem médico pra atender. O seu trabalho dependendo de outro colega. Isso deixa a gente mal [...] Isso é meio desgastante”.

Os problemas relacionados ao trabalho em equipe algumas vezes são atribuídos pelos trabalhadores a eles mesmos, outras ao gestor, ou ainda à falta de contratação de profissionais, porém uma visão mais ampla de como estão inseridos numa lógica capitalista de produção de saúde não fica clara. A excessiva normatização da ESF ao nível nacional, apontada por Franco e Merhy (2006), é reconhecida parcialmente pelos trabalhadores, mas de forma desarticulada do sistema social e econômico neoliberal em geral.

A desvalorização do agente comunitário de saúde apareceu diversas vezes nos depoimentos dos próprios trabalhadores dessa categoria, identificandose uma situação desconfortável de espera nos corredores, tentando realizar trocas de informações com a equipe entre uma consulta e outra. Além disso, há um rodízio constante no quadro de trabalhadoras dessa categoria, causando medo de desemprego. Assim elas preferem não dar opiniões sobre questões que possam comprometê-las:

\begin{abstract}
"E com isso você resolve não dar opinião. Porque eu já trabalhei em vários lugares e eu sei que sempre a parte mais fraca a corda rebenta. Se a gente cometer erro... eu fiquei extremamente magoada, que teve pessoas aqui que trabalham, eu não posso citar nomes, mas que cometeu erro grave e não foi mandada embora e uma amiga minha que é agente de saúde, não foi dado chance pra ela, mandaram embora. O que eu senti? A gente não é nada." (Entrevista)
\end{abstract}

A impossibilidade de a linguagem se materializar nas relações de trabalho cristalizava os sofrimentos e naturalizava-os como inevitáveis. O termo utilizado pela trabalhadora é contundente: "a gente não é nada". É a expressão literal da ruptura entre a condição de ser livre do ser humano e o próprio desejo capturado pelo desejo de outrem (Marx, 1844/2004).

Como já mencionado anteriormente, esta questão foi muito mais concernente à falta dela do que à sua presença. Conforme Merhy (2002), ela diz respeito à carência de tecnologias leves em favor das duras. A que mais trouxe desgaste foi a deficiência das leves, a começar pela falta de integração da equipe, que se esforça, mas não consegue superar os obstáculos a um trabalho mais coeso. A relação com o gestor municipal foi problemática, por causa das determinações rígidas; mas as dificuldades de gestão também se observam no interior da equipe. Atribui-se quase tudo que não dá certo ao gestor, desconhecendo-se as implicações do sistema econômico e político, bem mais abrangentes no tocante à saúde e à sociedade em geral.

\section{CONSIDERAÇÕES FINAIS}

De forma geral, o sofrimento apareceu como desânimo, angústia, conflito na equipe, falta de rede de apoio, acúmulo de atividades, atribuição dos problemas do usuário a si mesmo, desvalorização profissional, sobrecarga de trabalho e impotência ante a dificuldade de dar conta da demanda. Cabe salientar que os pressupostos da Saúde da Família baseiam-se numa reorientação do modelo e em rearranjos na organização do trabalho que consideram as múltiplas determinações do processo saúde-doença, o que deveria proporcionar autonomia e liberdade ao trabalhador; mas a perda 
do sentido no trabalho, pela fragmentação, e a falta de reconhecimento de si no trabalho, deixaram claro quanto, na lógica neoliberal e capitalista de produção, o trabalho não atende aos interesses e desejos do trabalhador, mas aos do mercado e do capital. A liberdade e a expressão do desejo foram capturadas e atreladas a outrem.

Assim, a política de saúde do trabalhador no SUS deve transformar ações individuais e momentâneas em ações coletivas e duradouras, no sentido de ampliar os espaços de discussão e dar voz ao trabalhador na sua coletividade. A palavra presa na garganta e o sofrimento utilizado como motor para aumento da produção foram os nós encontrados. Esses nós começaram a ser desatados, mas o trabalhador só se desvencilhará dos mecanismos defensivos quando puder abertamente compartilhar com seus pares outros caminhos mais saudáveis, em coletividade.

\section{REFERÊNCIAS}

Brasil (2004). Ministério da Saúde. Biblioteca Virtual em Saúde. Política Nacional de Educação Permanente dos trabalhadores do Ministério da Saúde (PNEP-MS). 2004. Disponível em: $<\mathrm{http}: / /$ bvsms.saude.gov.br/bvs/publicacoes/pnep.pdf $>$. Acesso em: 24 out. 2006.

Brasil (2006). Portaria n. 648/GM, de 28 de março de 2006. (2006, 29 de março). Aprova a Política Nacional de Atenção Básica, estabelecendo a revisão de diretrizes e normas para a organização da Atenção Básica para o Programa Saúde da Família (PSF) e o Programa Agentes Comunitários de Saúde (PACS). Diário Oficial da União, seção 1.

Campos, G. W. S. (2002). Subjetividade e administração de pessoal: considerações sobre modos de gerenciar o trabalho em equipes de saúde. Em E. E. Merhy \& R. Onocko (Orgs.), Agir em saúde: um desafio para o público (2 $2^{\mathrm{a}}$ ed., pp. 229-292). São Paulo: Hucitec.

Codo, W.; Sampaio, J. J. C., \& Hitomi, A. H. (1993). Indivíduo, trabalho e sofrimento: uma abordagem interdisciplinar. Petrópolis: Vozes.

Conselho Nacional de Saúde. (1996). Resolução 196/96 sobre pesquisa envolvendo seres humanos (pp. 15-25). Brasília: Ministério da Saúde.

Dejours, C. (1992). A loucura do trabalho: estudo de psicopatologia do trabalho (A. I. Paraguay, \& L. L. Ferreira, Trads., $5^{\text {a }}$ ed.). São Paulo: Oboré.

Dejours, C. (2004a). A metodologia em psicopatologia do trabalho. Em S. Lancman \& L. Sznelwar (Orgs.), Christophe Dejours: da psicopatologia à psicodinâmica do trabalho (pp. 105-126). Rio deJaneiro: Fiocruz.

Dejours, C. (2004b). Patologia da comunicação: situação de trabalho e espaço público. Em S. Lancman \& L. Sznelwar (Orgs.), Christophe Dejours: da psicopatologia à psicodinâmica do trabalho (pp.243-275). Rio de Janeiro: Fiocruz.

Dejours, C., \& Bègue, F. (2010). Suicídio e trabalho: O que fazer? (F. Soudant, Trad.) Brasília/DF: Paralelo 15.
Franco, T. B., \& Merhy, E. E. (2006). Programa de Saúde da Família (PSF): contradições de um programa destinado à mudança do modelo tecnoassistencial. Em E. E. Merhy, H. M. M. Junior, J. Rimoli, T. B. Franco \& W. S. Bueno. O trabalho em saúde: olhando e experienciando o SUS no cotidiano (pp. 53-160). São Paulo: Hucitec.

Heloani, J. R., \& Lancman, S. (2004). Psicodinâmica do trabalho: o método clínico de intervenção e investigação. Revista Produção, 14 (3), 77-86.

Kantorski, L. P. (1997). As transformações no mundo do trabalho e a questão da saúde - algumas reflexões preliminares. Rev.latinoam.enfermagem, 5 (2), 5-15.

Lima, M. E. A. (2002). Esboço de uma crítica à especulação no campo da saúde mental e trabalho. Em M. da G Jacques \& W. Codo. (Orgs.), Saúde mental \& trabalho: leituras (pp. 50-81). Petrópolis: Vozes.

Martins, S. T. F. (2003). Processo grupal e a questão do poder em Martin-Baró. Psicologia \& Sociedade, 1(15), 201-217.

Marx, K. (2004). Trabalho alienado. Em K. Marx, Manuscritos econômicos-filosóficos (A. Martins, Trad, pp. 110-122). São Paulo: Martin Claret. (Original publicado em 1844).

Matumoto, S., Fortuna, C. M., Mishima, S. M., Pereira, M. J. B., \& Domingos, N. A. M. (2005). Supervisão de equipes no Programa de Saúde da Família: reflexões acerca do desafio da produção de cuidados. Interface-Comunicação, Saúde e Educação, 16(9), 924.

Merhy, E. E. (2002). Saúde: a cartografia do trabalho vivo. São Paulo: Hucitec.

Minayo, M. C. S. (2004). O desafio do conhecimento: pesquisa qualitativa em saúde ( $8^{\mathrm{a}}$ ed.). Rio de Janeiro: Hucitec.

Peduzzi, M. (2001). Equipe multiprofissional de saúde: conceito e tipologia - atualização. Revista de Saúde Pública, 1(35), 103-109.

Pires, D. (2000). Reestruturação produtiva e consequências para o trabalho em saúde. Revista Brasileira de Enfermagem, 2(53), 251-263.

Ribeiro, E. M.; Pires, D., \& Blank, V. L. (2004). A teorização sobre o processo de trabalho em saúde como instrumental para análise do trabalho no Programa de Saúde da Família. Cadernos de Saúde Pública, 2(20), 438-446.

Ribeiro, S.F.R., \& Martins, S.T.F. (2007). Oficina de teatro espontâneo com trabalhadores do Programa de Saúde da Família: um espaço de expressão e reflexão. Pesquisas e Práticas Psicossociais, 2(1), p.221-28.

Sato, L., \& Bernardo, M.H. (2005). Saúde mental e trabalho: os problemas que persistem. Ciênc. Saúde Colet., v.10, n.4, p.869$878,2005$.

Seligmann-Silva, E. (1994). Desgaste mental no trabalho dominado. Rio de Janeiro: Cortez.

Seligmann-Silva, E. (2003). Psicopatologia e saúde mental no trabalho. Em R. Mendes, Patologia do trabalho (pp. 1142-1182). São Paulo: Ateneu.

Silva, I. Z. Q. J., \& Trad, L. A. B. (2005). O trabalho em equipe no PSF: investigando a articulação técnica e a interação entre os profissionais. Interface - Comunicação, Saúde e Educação, 16(9), 25-38. 
Teixeira, R. A.; Mishima, S. M., \& Pereira, M. J. B. (2000). O trabalho de enfermagem em atenção primária à saúde - a assistência à saúde da família. Revista Brasileira Enfermagem, 2(53), 193-206.

Vieira, C. M., \& Cordeiro, M. P. (2005). Trabalho e subjetividade: intervenção psicossocial envolvendo uma equipe de profissionais do "Programa Saúde da Família". Arquivos Brasileiros de Psicologia, 1(57), 58-74.
Vigotski, L.S. (1995) Historia del desarrollo de las funciones psíquicas superiores. Em L.S. Vigotski. Problemas del desarrollo de la psique. (L. Kuper, Trad, pp.09-340). Madrid: Visor Dist. (Obras escogidas, III) (Original publicado em 1931).

Recebido em 03/07/2008

Aceito em 07/06/2011

\section{Endereço para correspondência:}

Sandra Fogaça Rosa Ribeiro. Rua Emílio Trevisan, 626, Jardim Bela Daria, CEP19 013200, Presidente Prudente-SP, Brasil.E-mail: sandrafogacarr@gmail.com. 